\title{
Band-Gap Engineering: A New Tool for Tailoring the Activity of Semiconducting Oxide Catalysts for CO Oxidation
}

Hongmin Zhang ${ }^{\dagger}$, Zhiqiang Zhang $\dagger$, Yameng Liu, Xiuzhong Fang, Junwei Xu, Xiang Wang*, Xianglan Xu* 


\section{Catalyst Characterization}

The X-ray diffraction (XRD) patterns were recorded on a Bruker AXSD8Focus diffractometer instrument operating at $40 \mathrm{kV}$ and $40 \mathrm{~mA}$, with $\mathrm{Cu}$ target $K_{\alpha}$ irradiation $(\lambda=1.5405 \AA)$.

High-resolution transmission electron microscopy (HR-TEM) images were obtained on a Tecnai ${ }^{\mathrm{TM}}$ F30 transmission electron microscope.

Inductively coupled plasma-atomic emission spectroscopy (ICP-AES) was measured with an ICP-715ES (Varian) to detect the bulk elemental compositions of the samples.

The specific surface areas, pore volumes and pore diameters of the samples were measured by nitrogen adsorption-desorption at $77 \mathrm{~K}$ on ASAP 2020 instrument. The specific surface area and pore size distribution were calculated by the BET method and BJH methods, respectively.

Raman spectra were recorded on a Renishaw inVia Raman spectrometer with an excitation wavelength of $532 \mathrm{~nm}$ and the laser power of $5 \mathrm{~mW}$.

The X-ray photoelectron spectroscopy (XPS) tests were carried out on a PerkinElmer PHI1600 system using a single $\mathrm{Mg} \mathrm{K}$ X-ray source operating at $300 \mathrm{~W}$ and $15 \mathrm{kV}$. The spectra were obtained at ambient temperature with an ultrahigh vacuum. The binding energy was calibrated using the $\mathrm{C} 1 \mathrm{~s}$ peak at $284.5 \mathrm{eV}$ as the internal standard.

Oxygen temperature programed desorption $\left(\mathrm{O}_{2}-\mathrm{TPD}\right)$ experiments were performed on Micromeritics ASAP2920 instrument. Typically, $50 \mathrm{mg}$ of sample was placed in a quartz reactor, pretreated in He flow at 200 ${ }^{\circ} \mathrm{C}$ for $1 \mathrm{~h}$, then saturated in a $30 \mathrm{~mL} \mathrm{~min}-13 \% \mathrm{O}_{2}$ (He balanced) flow at $50{ }^{\circ} \mathrm{C}$ for $1 \mathrm{~h}$. Afterwards, the sample was purged with a $30 \mathrm{~mL} \mathrm{~min}{ }^{-1}$ ultra-high purity (UHP) He flow for 30 min to remove any physically adsorbed $\mathrm{O}_{2} . \mathrm{O}_{2}$-TPD was then carried out from $50{ }^{\circ} \mathrm{C}$ to $800{ }^{\circ} \mathrm{C}$ with a heating rate of $10{ }^{\circ} \mathrm{C} \mathrm{min}{ }^{-1}$ in a $30 \mathrm{~mL} \mathrm{~min}^{-1}$ UHP He flow. A thermal conductivity detector (TCD) was used to monitor the signals. The $\mathrm{O}_{2}$ desorption numberof the catalysts were quantified by using a $\mathrm{KMnO}_{4}(99.0 \%)$ standard, which decomposes completely to $\mathrm{K}_{2} \mathrm{MnO}_{4}, \mathrm{MnO}_{2}$ and $\mathrm{O}_{2}$ at around $300{ }^{\circ} \mathrm{C}$ according to the stoichiometry. 
2. Supplementary Results

(a)

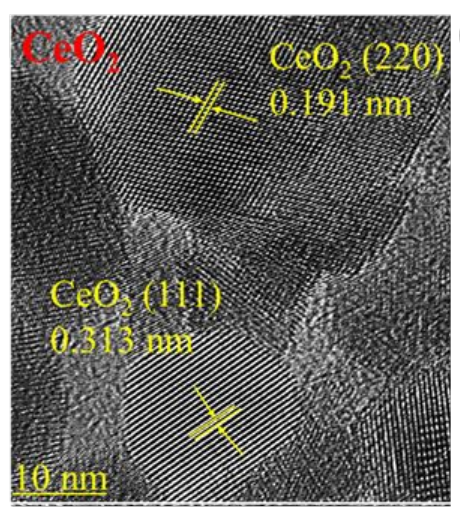

(d)

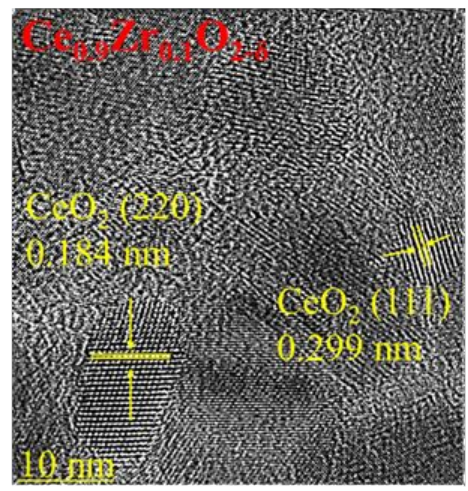

(b)

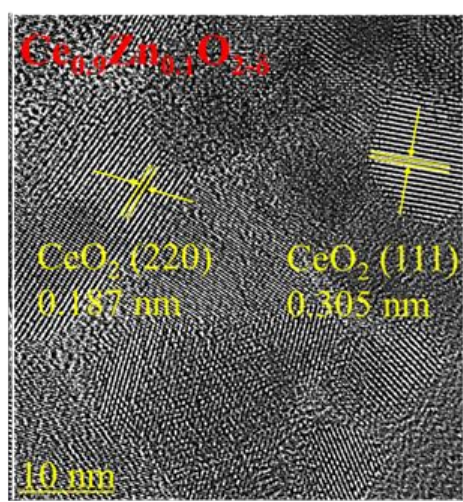

(e)

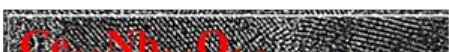

(c)

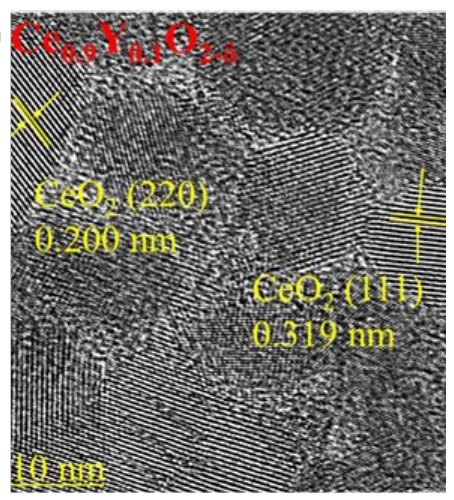

Figure S1 HR-TEM images of the samples: (a) $\mathrm{CeO}_{2}$ (b) $\mathrm{Ce}_{0.9} \mathrm{Zn}_{0.1} \mathrm{O}_{2-\delta}$ (c) $\mathrm{Ce}_{0.9} \mathrm{Y}_{0.1} \mathrm{O}_{2-\delta}$ (d) $\mathrm{Ce}_{0.9} \mathrm{Zr}_{0.1} \mathrm{O}_{2-\delta}$ (e) $\mathrm{Ce}_{0.9} \mathrm{Nb}_{0.1} \mathrm{O}_{2-\delta}$ 

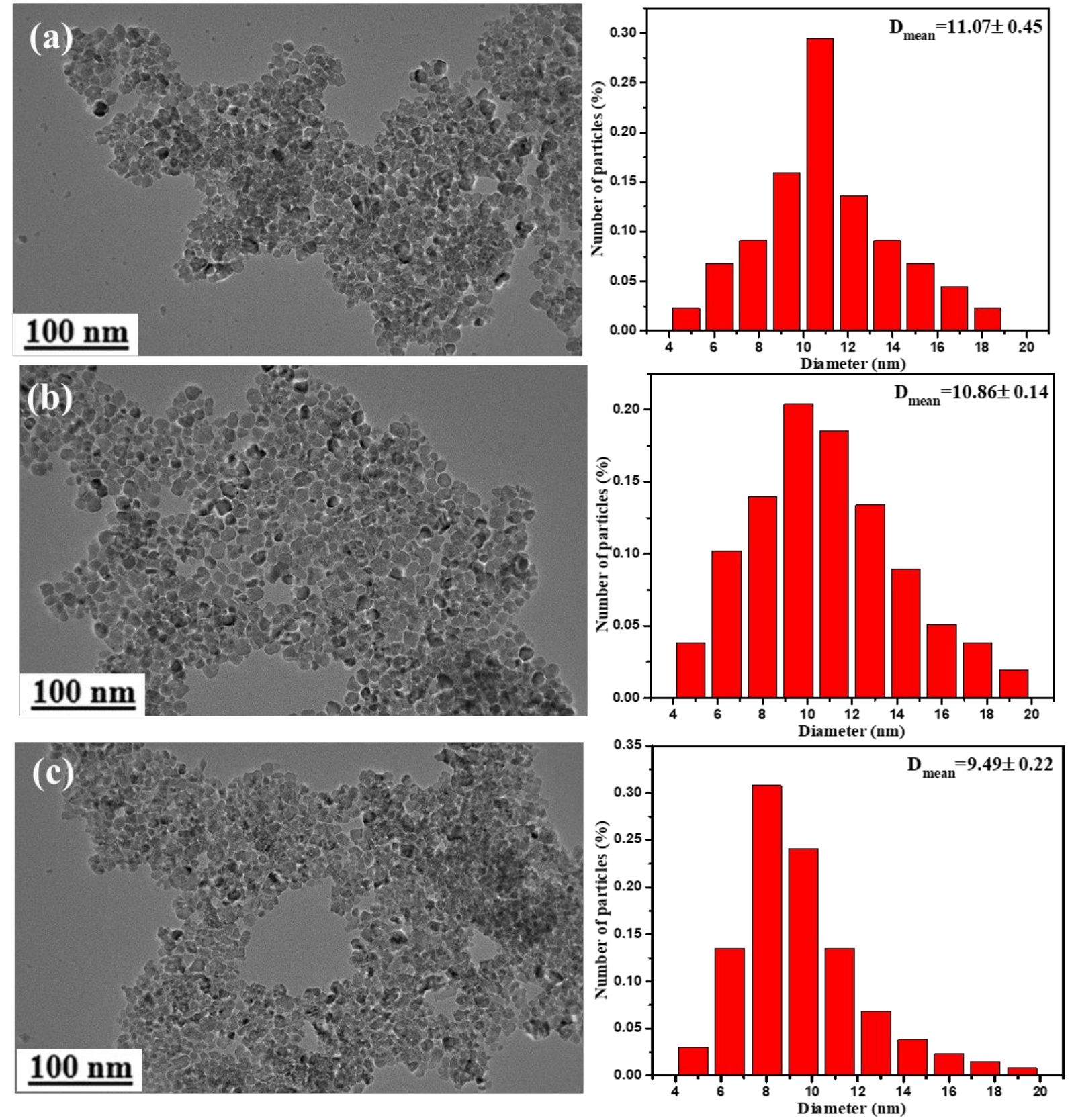

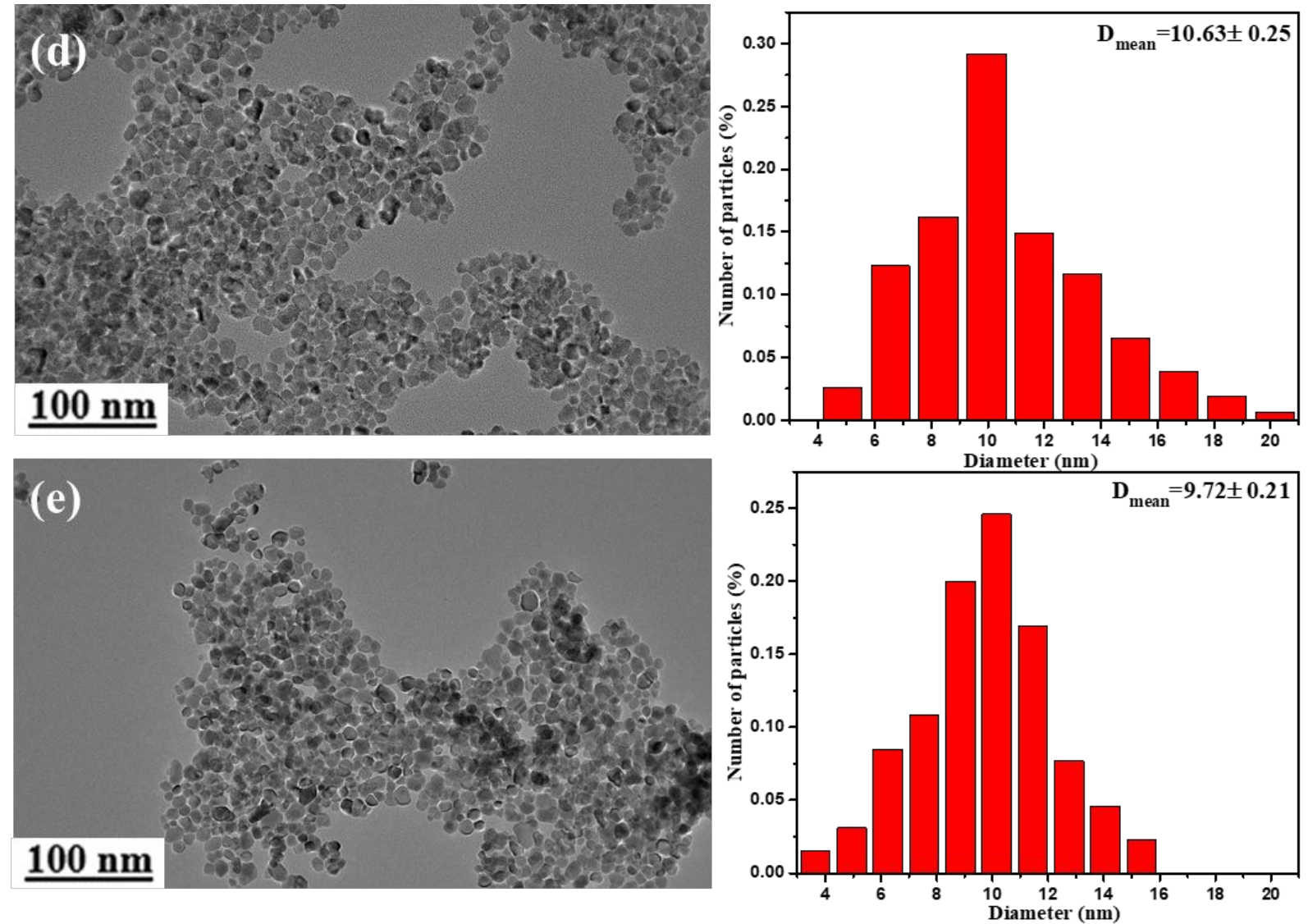

Figure S2 TEM images of the samples: (a) $\mathrm{CeO}_{2}$ (b) $\mathrm{Ce}_{0.9} \mathrm{Zn}_{0.1} \mathrm{O}_{2-\delta}$ (c) $\mathrm{Ce}_{0.9} \mathrm{Y}_{0.1} \mathrm{O}_{2-\delta}$ (d) $\mathrm{Ce}_{0.9} \mathrm{Zr}_{0.1} \mathrm{O}_{2-\delta}$ (e) $\mathrm{Ce}_{0.9} \mathrm{Nb}_{0.1} \mathrm{O}_{2-\delta}$

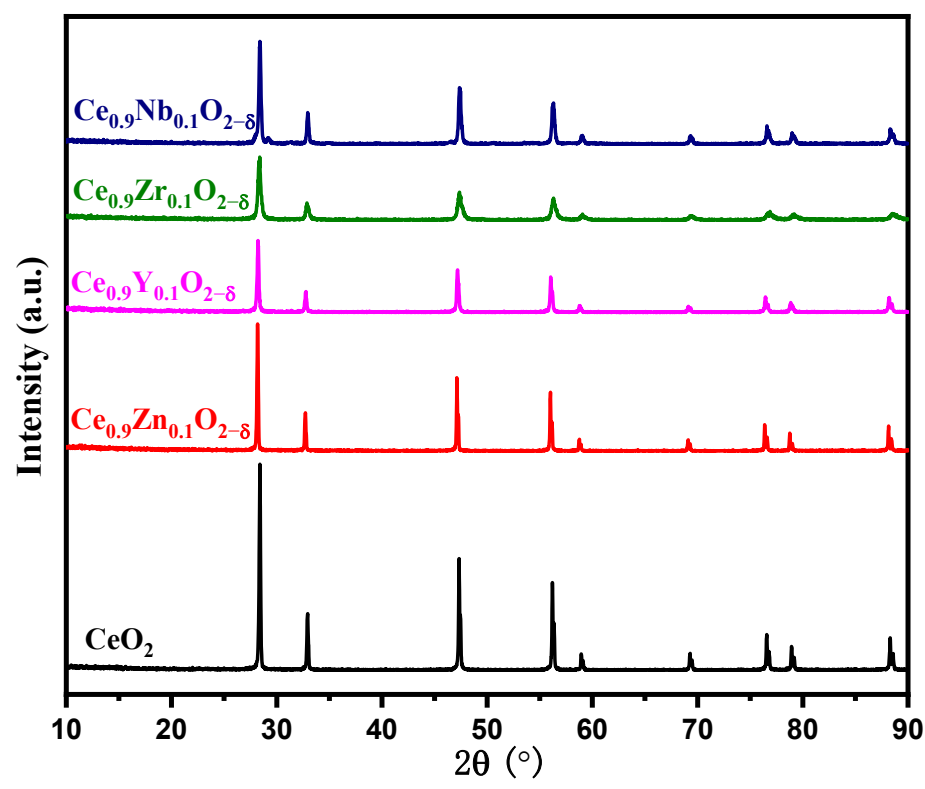

Figure S3 XRD patterns of the $\mathrm{Ce}_{0.9} \mathrm{M}_{0.1} \mathrm{O}_{2-\delta}$ samples calcined at $1000{ }^{\circ} \mathrm{C}$. 

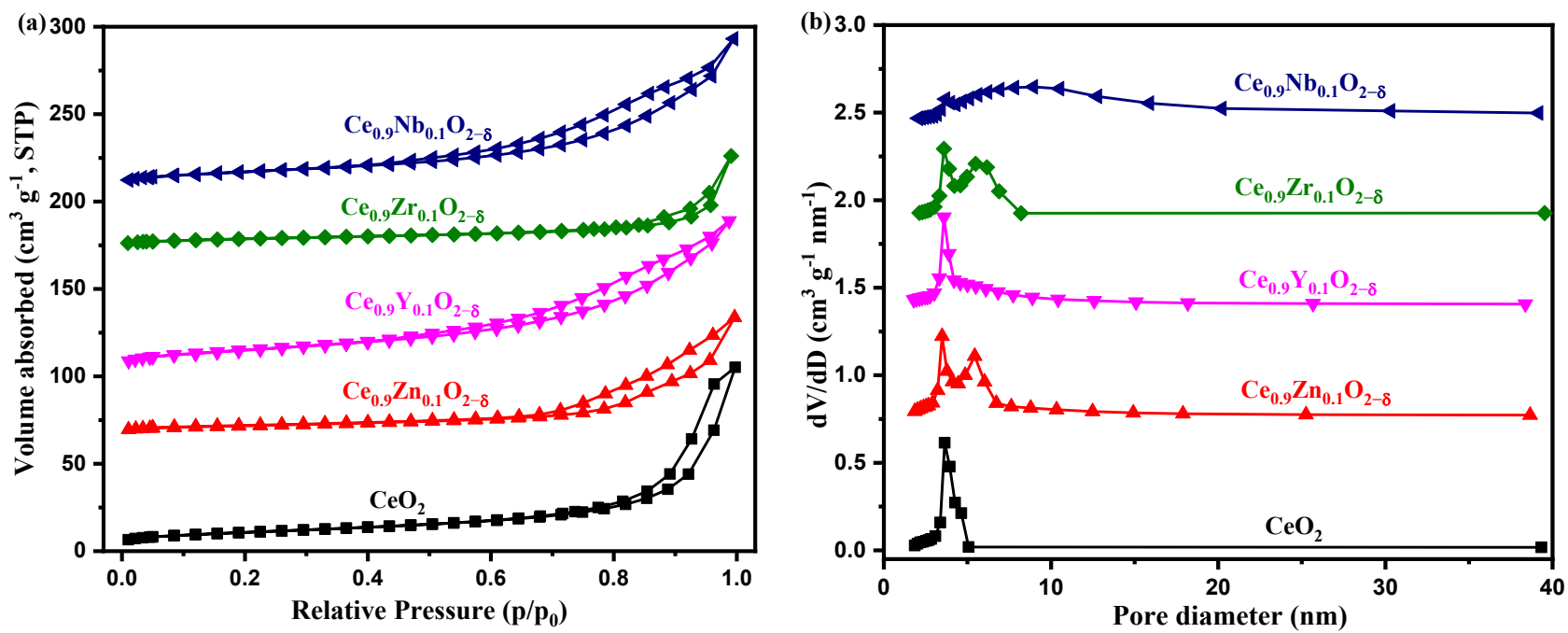

Figure S4 (a) $\mathrm{N}_{2}$ adsorption-desorption isotherms and (b) pore-size distributions profiles of the $\mathrm{Ce}_{0.9} \mathrm{M}_{0.1} \mathrm{O}_{2-\delta}$ samples 

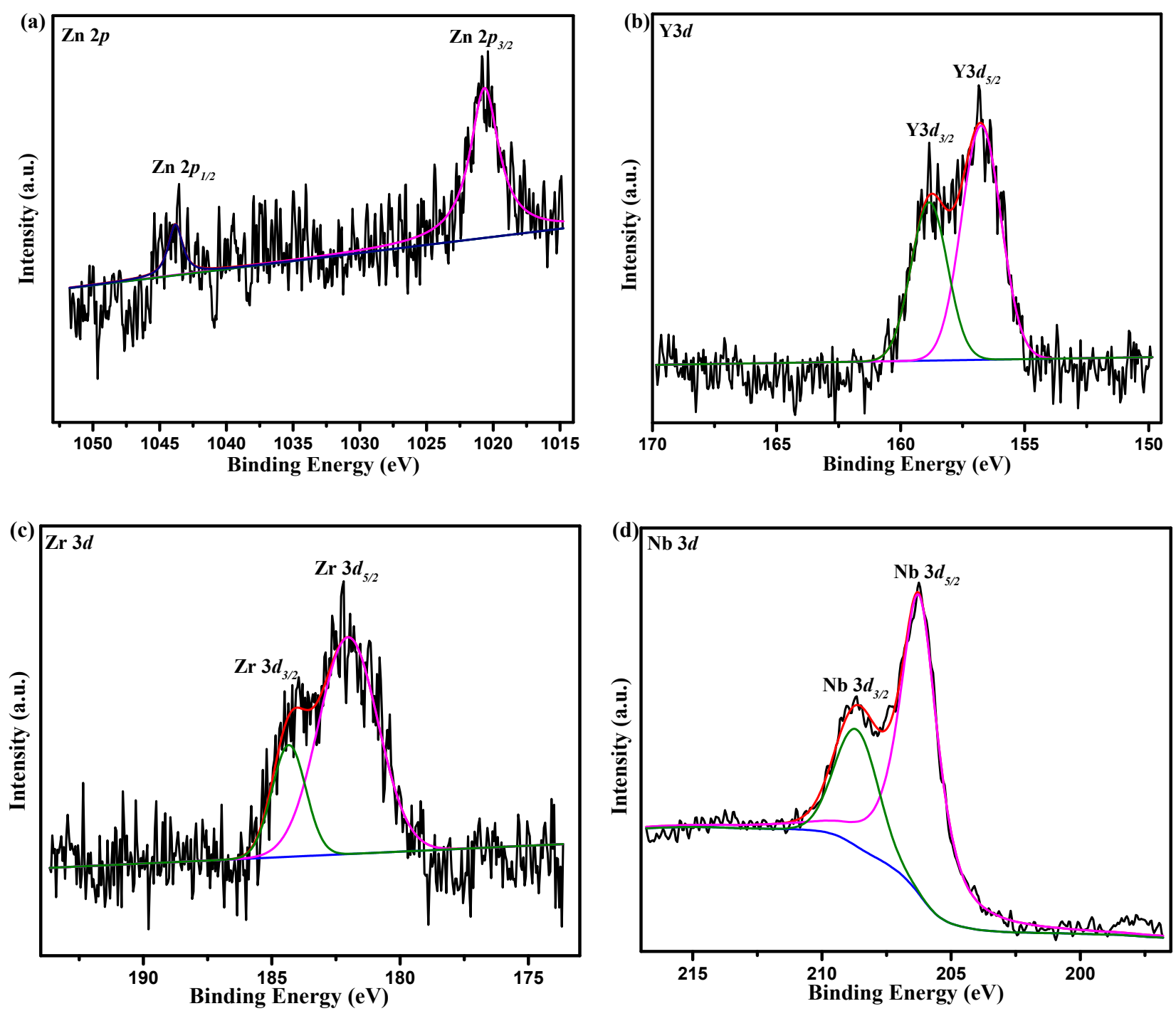

Figure S5 XPS spectra of the doping cations (a) Zn $2 p$ (b) Y $3 d$ (c) Zr $3 d$ (d) Nb $3 d$ 

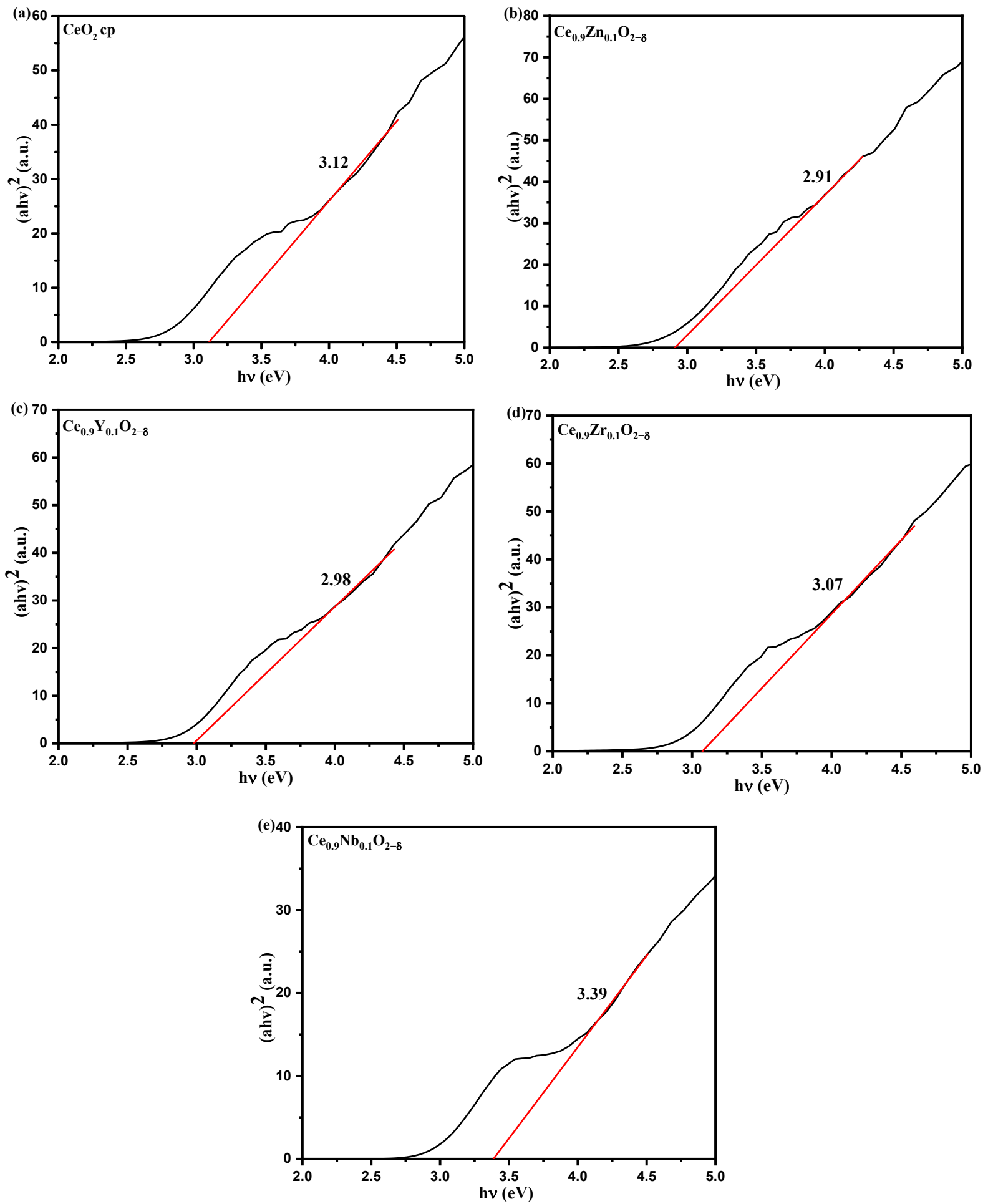

Figure S6 Tauc plots for band gap of the $\mathrm{Ce}_{0.9} \mathrm{M}_{0.1} \mathrm{O}_{2-\delta}$ samples. 


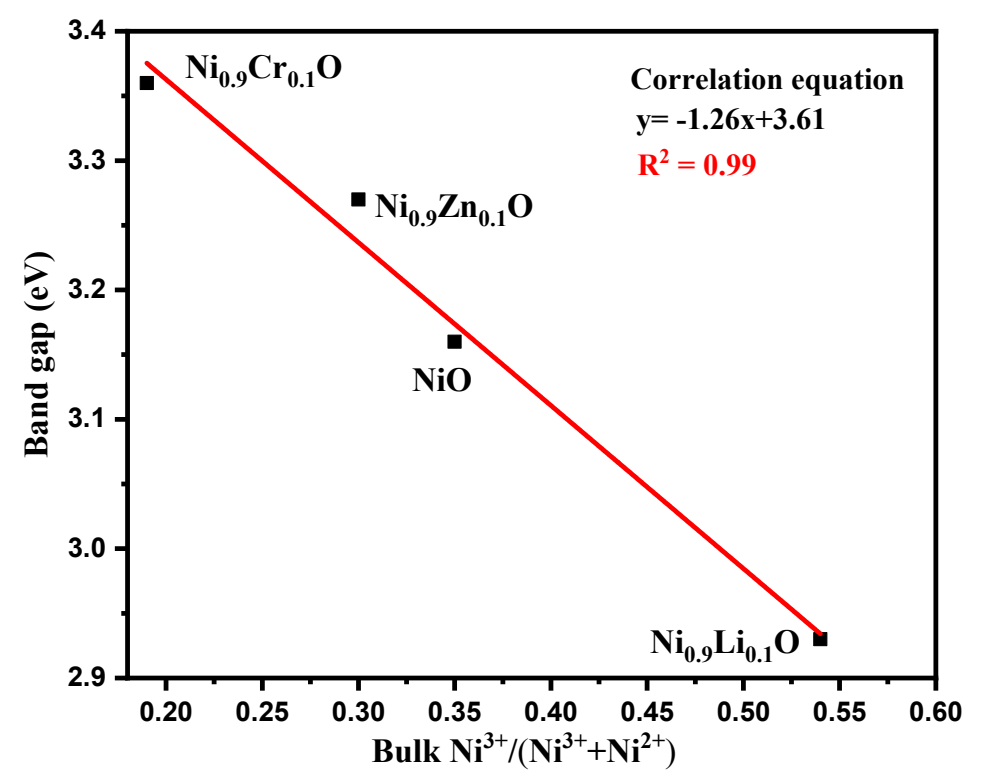

Figure $\mathbf{S} 7$ The correlation between band gap and bulk $\mathrm{Ni}^{3+} /\left(\mathrm{Ni}^{3+}+\mathrm{Ni}^{2+}\right)$ of $\mathrm{Ni}_{0.9} \mathrm{M}_{0.1} \mathrm{O}$. 